\title{
Effects of dynamic workstation Oxidesk on acceptance, physical activity, mental fitness and work performance
}

\author{
L. Groenesteijn ${ }^{\mathrm{a}, \mathrm{b}, *}$, D.A.C.M. Commissaris ${ }^{\mathrm{c}}$, M. Van den Berg-Zwetsloot ${ }^{\mathrm{d}}$ \\ and S. Hiemstra-Van Mastrigt ${ }^{\mathrm{a}, \mathrm{e}}$ \\ ${ }^{a}$ Department of Applied Ergonomics and Design, Delft University of Technology, Faculty of Industrial Design, \\ Delft, The Netherlands \\ ${ }^{\mathrm{b}}$ Charly Green, Bilthoven, The Netherlands \\ ${ }^{\mathrm{c}}$ BTR Coaching \& Consultancy, Helvoirt, The Netherlands \\ ${ }^{\mathrm{d}}$ Studelta, Amsterdam, The Netherlands \\ ${ }^{\mathrm{e}}$ TNO Work and Employment, Leiden, The Netherlands
}

Received 2 February 2015

Accepted 24 June 2015

\begin{abstract}
.
BACKGROUND: Working in an office environment is characterised by physical inactivity and sedentary behaviour. This behaviour contributes to several health risks in the long run. Dynamic workstations which allow people to combine desk activities with physical activity, may contribute to prevention of these health risks.

OBJECTIVE: A dynamic workstation, called Oxidesk, was evaluated to determine the possible contribution to healthy behaviour and the impact on perceived work performance.

METHODS: A field test was conducted with 22 office workers, employed at a health insurance company in the Netherlands. RESULTS: The Oxidesk was well accepted, positively perceived for fitness and the participants maintained their work performance. Physical activity was lower than the activity level required in the Dutch guidelines for sufficient physical activity.

CONCLUSIONS: Although there was a slight increase in physical activity, the Oxidesk may be helpful in the reducing health risks involved and seems applicable for introduction to office environments.
\end{abstract}

Keywords: Office work, physical inactivity, prevention

\footnotetext{
*Address for correspondence: Liesbeth Groenesteijn, Charly Green, Bors van Waverenstraat 18, 1181 SM Amstelveen, The Netherlands. Tel.: +31 $611132 \quad 31$ 39; E-mail: liesbeth @ charlygreen.nl.
}

\section{Introduction}

When people sit still for too long without sufficient active breaks, this is called sedentary behaviour. In the long term, such behaviour can result in several health issues, such as type II diabetes, cardiovascular disorders and even premature death [1]. Sedentary 
behaviour and physical inactivity are independent health risks; even with regular exercise, people are still exposed to increased health risks if they have a sedentary lifestyle [2]. As there is no commonly accepted definition of sedentary work, the number of persons exposed to the sedentary work related health risks is difficult to estimate the numbers of persons. In the Netherlands, about $50 \%$ of the adult working population reports sitting 4 or more hours per day at work [3]. In the USA, Church et al. [4] stated that in 2008 , about $25 \%$ of all occupations had a sedentary character, whereas this was only $15 \%$ in 1960 were sendentary. In the USA, sedentary occupations are, as in the Netherlands, predominantly located in sectors information, financial activities, and professional and business services.

In order to present a solution, an office furniture manufacturer and product designer jointly developed a flexible dynamic workstation called Oxidesk (see Fig. 1). The development of the Oxidesk began at the end of 2009. At that time, the scientists who initiated the development were not aware of the health risks of sedentary work. The aim of the Oxidesk was to contribute to the recommended daily amount of moderately intense physical activity by incorportating that activity in the office. This was in line with recommendations that TNO issued in 2006 [5] and remained the primary aim of the Oxidesk, even after the managing scientists learned about health risks of sedentary work. The Oxidesk workstation should allow employees to efficiently combine various office chores with exercise. In the comparison of three different dynamic workstations [6], it was concluded that with the exception of high precision mouse tasks, the measured short-term work performance was not affected by working on a dynamic workstation. A field evaluation study was conducted with the Oxidesk.

The research questions were:

Could the Oxidesk substantially contribute to more physical activity, without loss of quality or quantity of office work being performed at the same time?

What is the acceptance of this innovative concept, and what are the perceptions of the mental and the physical fitness?

\section{Materials and methods}

Twenty-two office workers, employed at an insurance company in the Netherlands, voluntarily participated in the evaluation study. The average

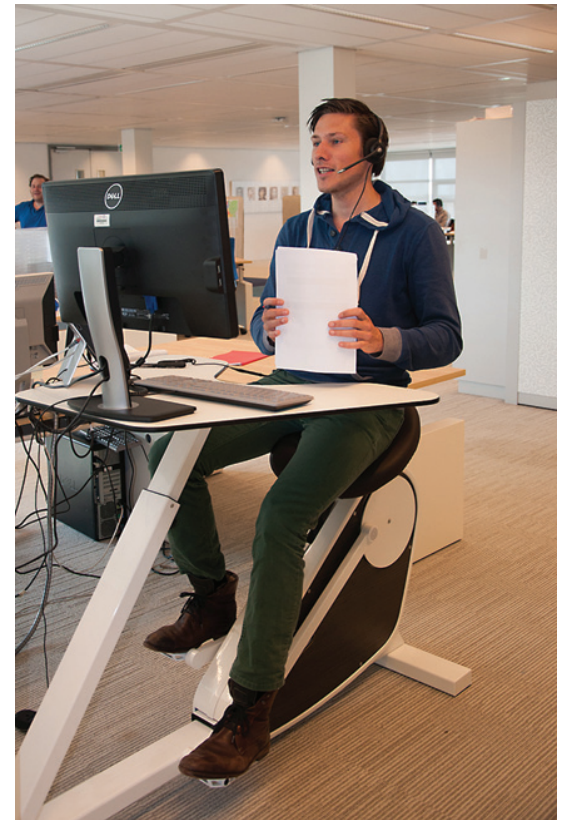

Fig. 1. The Oxidesk workstation used by a participant of the field test.

age of the participants was 26.5 years $(\mathrm{SD}=6.0)$, $59 \%$ were male, their average height was $1.79 \mathrm{~m}$ $(\mathrm{SD}=9.3)$, and average weight $75.2 \mathrm{~kg}(\mathrm{SD}=10.4)$. During a 5-week period, they actively used the Oxidesk at least 6 times a week for 30 minutes while performing their regular work.

Preceding the first use of the Oxidesk, the participants were asked to complete an intake questionnaire about the attractiveness for use, and the match with the working environment, to determine the participants' expectations. After the first and the last use of the Oxidesk, a second questionnaire was completed on acceptance, physical activity, Locally Perceived Discomfort (LPD), mental fitness and work performance. For the period of use in between the first and the last use of the Oxidesk, participants also completed a logbook about the duration of use and the tasks performed while using the Oxidesk. At the end of the 5-weeks period, immediately following the last time use, they were asked to pass a final assessment. During the first and the last use, a heart rate monitor was used to establish the physical activity level while using the Oxidesk.

Frequencies of questionnaire scores were determined and open answer comments were categorized. A paired $t$-test was used to compare discomfort (LPD) before and after Oxidesk use (level of significance $P<0.05)$. Using the heart rate measurements the 


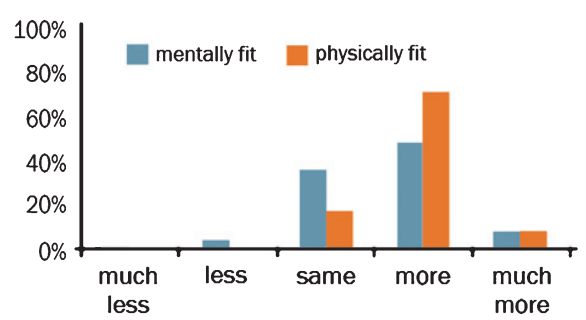

Fig. 2. Experienced level of mental and physical fitness while using the Oxidesk in comparison to using a regular workstation $(n=22)$.

\% heart rate reserve (HRR) was calculated by subtracting the resting heart rate from the predicted maximum heart rate.

\section{Results}

\subsection{Physical activity, fitness and LPD}

According to the intake questionnaire, $73 \%$ of the participants met the standards set by the Dutch government for healthy behaviour [5] concerning the amount of physical activity. Also, the majority of participants $(73 \%)$ said they practiced sports on 2 or more days each week. The average Heart Rate Reserve in the first and the last time Oxidesk use was $22 \%$ and $19 \%$ respectively.

The overall opinion of the participants concerning the contribution of the Oxidesk to their mental and physical fitness was positive. After a session on the Oxidesk, $82 \%$ of the participants stated to feel more physically fit and 59\% experienced an increased mental fitness (see Fig. 2). In the comments, subjects described their feelings after the last session on the Oxidesk as more fit, more energetic, sharper, more rested and more alert.

The difference in LPD scores before and after Oxidesk use (see Fig. 3) significantly increased during the first Oxidesk use $(p=0.04)$ and was experienced in shoulders, back, buttock, and thigh areas. During the last Oxidesk use there was no significant difference between before and after, and the number of areas with discomfort was reduced. The most prominent areas with discomfort were buttocks and thighs. Approximately half of the participants, especially men, commented on the shape and/or position of the saddle in terms of a too wide shape at the front or an uncomfortable angle of the saddle.
First time Oxidesk use

Last time Oxidesk use
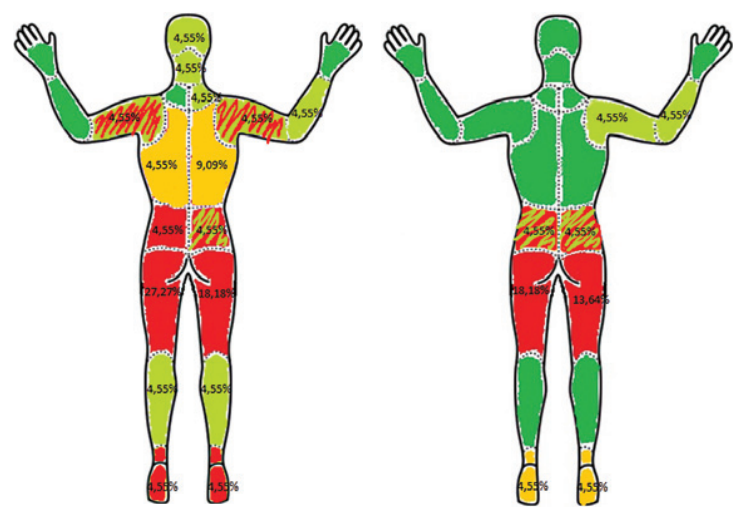

Fig. 3. Locally Perceived Discomfort per body region (no discomfort 0-10 extreme discomfort) during the first and the last time Oxidesk use. The colours indicate the magnitude between the scores before and after Oxidesk use: Light green: decrease LPD score. Green: equal score. Yellow: +1 increase. Rood: $\geq 2$ increase. The percentages of participants that scored the LPD area are shown in the body areas.

\subsection{Work performance perception}

After the 5-week testing period, the majority of the subjects said that job performance for all tested desk activities on the Oxidesk was equal to the job performance at a traditional workstation consisting of an office chair and desk (see Fig. 4). During typing, $64 \%$ of the participants said speed and accuracy were at least equal to their regular workstation. While performing mouse work, speed and accuracy were of the same level according to almost $80 \%$ of the participants, similar to reading. Seventy seven percent of the participants said that the level of concentration was at least maintained while working at the Oxidesk. Thirty six percent actually experienced and increased level of concentration while using the Oxidesk.

\subsection{Acceptance}

When asked about their expectations before ever seeing the Oxidesk or knowing the purpose of the test, $82 \%$ of the test subjects said they were in need of more physical activity opportunities at work. The same majority expected that a dynamic workstation would contribute to a large (32\%) to very large (55\%) fulfillment of their needs for more activity.

After the first experience adjusting the Oxidesk, $86 \%$ of the participants knew how to adjust the Oxidesk afterwards. The time needed for adjustment 


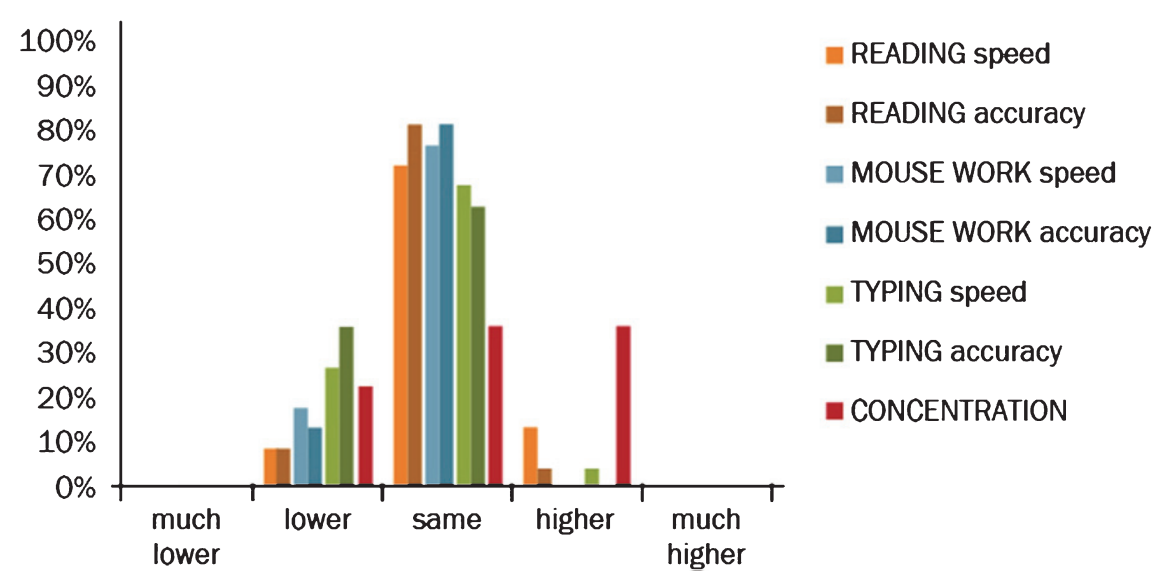

Fig. 4. Experienced work performance for several desk activities (reading, doing mouse work, typing and concentration) while using the Oxidesk in comparison to using a regular workstation $(n=22)$.

was judged to be short or very short by $82 \%$ of the participants.

Ninety one percent of the participants thought the Oxidesk would not need a separate workspace for proper integration into an office. They had no reservations using the Oxidesk in front of their colleagues. Sixty eight percent of the participants wanted to continue using the Oxidesk in the future. Eighty six percent of the subjects thought the Oxidesk would be suitable for their work department. Eithy two percent of the subjects thought the Oxidesk could replace some of the existing flexible workstations in their department (see Fig. 5). There were also negative comments concerning design parts. Approximately half of the participants commented on the shape and/or the position of the saddle. Additionally, the surface of the table was perceived too small for the work performed by $14 \%$ of the participants.

For $14 \%$ of the participants, the pedalling motion should have been smoother with a more rounded movement. According to the participants, adding a feedback display of speed, distance and calories burned would have increased the added value of the Oxidesk.

\section{Discussion}

The present study evaluated the contribution of the Oxidesk dynamic workstation to increase physical activity and the effects on perceived work performance, LPD, acceptance and mental and physical fitness.

According to the intake questionnaire, $73 \%$ of the participants met the standards set by the Dutch government for healthy behaviour concerning the amount of physical activity. This percentage was higher than the Dutch average for the whole population (59\%). Also, the majority of participants (73\%) said they practiced sports on two or more days each week. Together with self-selection by voluntary participation, and possibly higher health awareness as health insurance employees, the research population was biased. The representation of these results for a broader group of office workers is therefore limited.

The Dutch guideline, which is in line with international guidelines for sufficient physical activity, stipulates that people should perform half an hour of moderate activity each day for at least 5 days a week. For most people, moderate activity is comparable to a brisk walk. The intensity of physical activity can be quantified using the heart rate elevation: physical activity is moderate at a heart rate of at least $40 \%$ of the Heart Rate Reserve (HRR) [7]. During the test with the Oxidesk, the average HRR of the participants was $20 \%$. This indicates an increased heart rate, but is insufficient to qualify as moderate activity. This low outcome may be attributed to the relatively young and fit test group who need a higher intensity to raise the heart rate compared to average persons. Furthermore, the main task of the test group was to conduct phone calls with external customers. Perhaps the self-chosen pedalling frequency was kept lower to avoid an increased respiration frequency, resulting in a lower HRR.

In order to be accepted for employers as well as employees, it is of vital importance that both quality and quantity of work at least be maintained whilst using the Oxidesk. After using the Oxidesk for at least 6 times for half an hour, the majority of the subjects 


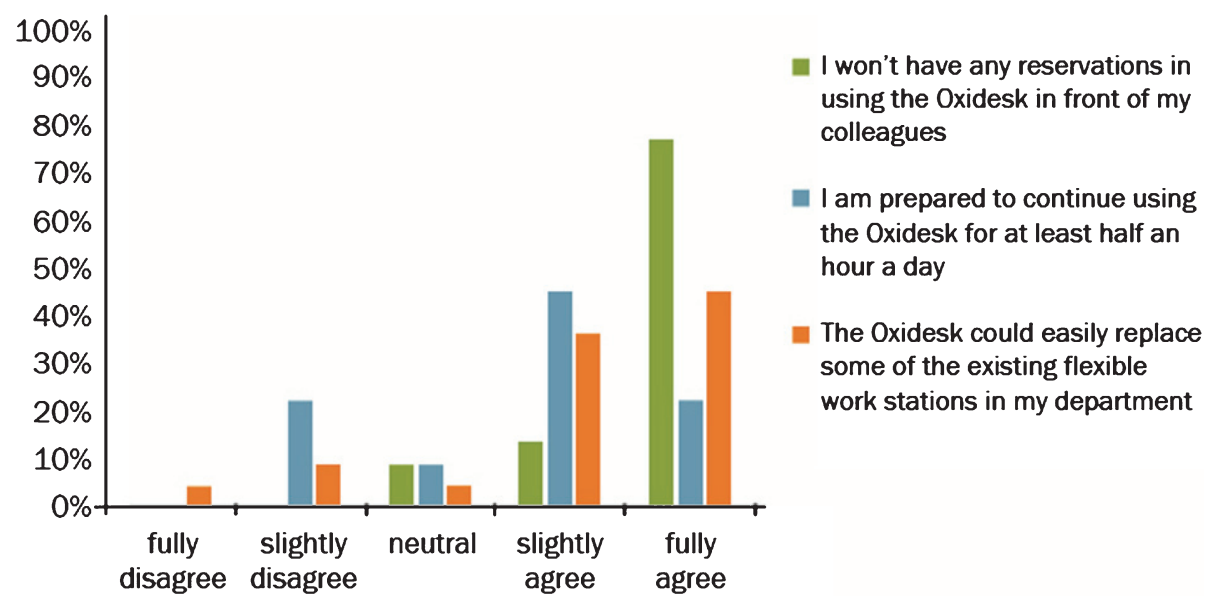

Fig. 5. Answers to the statements concerning the acceptability of the Oxidesk $(n=22)$.

said that job performance for all tested desk activities was at least equal to the job performance at a traditional work station consisting of an office chair and desk. This is in line with other studies [8-10], who also reported no decline in perceived performance while using dynamic workstations. However, it is in contrast with the results of the study by Commissaris et al. [6], who found that perceived performance was reduced when working at a dynamic workstation. The objectively measured performance was not reduced with the exception of the high precision mouse tasks. Preferably, both the perceived and the objectively determined performance remained at least the same compared to a traditional workstation.

For discomfort the most prominent LPD regions, namely buttocks and thighs, could be related to the shape and/or the position of the saddle which was mentioned in the questionnaire comments. Possibly, a different design and angle of the saddle would reduce the discomfort level. Apart from this, the difference in perceived LPD during the first and the last Oxidesk use was remarkable. During the first use there was a significant increase in discomfort. During the last use this increased was not measured. One explanation could be a certain habituation to the exercise and acceptance of some discomfort related to the physical activity, which was shown in other studies $[11,12]$. Another possible explanation was that the first use was more intense in contrast to the original office chair, as they had no previous experience with dynamic workstations. An office chair has different seat shapes and is moreover equipped with a backrest. The use of the backrests takes of the biomechanical load off the back and improves the comfort experience [13]. The Oxidesk has no backrest and may therefore be experienced as less comfortable as compared with an office chair.

The overall acceptance of the Oxidesk was high. The Oxidesk was perceived as easy to use and quick to adjust. The majority of the participants did not feel any reservations towards using the Oxidesk in an office environment and did not feel the need for a separate workspace. Of the participants, $68 \%$ were prepared to continue using the Oxidesk on a daily basis, while $41 \%$ wanted to use the Oxidesk an hour or longer each day. Two studies $[9,10]$, found similar results in which test participants wanted to continue the use of a treadmill and a pedal exercise machine after the test period in their work environments.

The Oxidesk appears applicable for broader introduction to reduce physical inactivity in office environments, while maintaining the same level of work performance. The increase in physical activity according to the Heart Rate Reserve (HRR) is lower than the $40 \%$ HRR needed to meet the activity level as required in the Dutch guideline for sufficient physical activity. However, there is emerging evidence that increasing the amount of light-intensity physical activity throughout sedentary work day can have health benefits [14-16]. In that case, regularly using the Oxidesk might contribute to healthier behavior for many people with a profession that provokes sedentary behavior. Further research is needed to clarify this assumption.

\section{Acknowledgments}

This project was initiated by Markant, Vormdrift and TNO and funded by the SBIR programme of 
TNO. We would like to thank Achmea and their employees for facilitating the test location and for their participation in the study.

\section{Conflict of interest}

The authors have no conflict of interest to report.

\section{References}

[1] Wilmot EG, Edwardson CL, Achana FA, et al. Sedentary time in adults and the association with diabetes, cardiovascular disease and death: Systematic review and meta-analysis. Diabetologia 2012;55(11):2895-905.

[2] Van der Ploeg HP, Chey T, Korda RJ, Banks E, Bauman A. Sitting time and all-cause mortality risk in 222497 Australian adults. Arch Intern Med 2012;172:494-500.

[3] Bakhuys Roozeboom M, de Vroome E, Smulders P, van den Bossche S. Trends in de arbeid in Nederland tussen 2000 en 2004 (Trends in work in The Netherlands between 2000 and 2004). TNO Kwaliteit van Leven, Hoofddorp. 2007.

[4] Church TS, Thomas DM, Tudor-Locke C, Katzmarzyk PT, Earnest CP, Rodarte RQ, Martin CK, Blair SN, Bouchard C. Trends over 5 decades in U.S. occupation-related physical activity and their associations with obesity. PLoS ONE 2011;6:1-7.

[5] Commissaris DACM, Douwes M, Schoenmaker N, de Korte EN. Recommendations for sufficient physical activity at work. Proceedings of the IEA 2006 conference, Maastricht (CD-rom), 2006.

[6] Commissaris DACM, Konemann R, Hiemstra-van Mastrigt S, Burford EM, Botter J, Douwes M, Ellegast RP. Effects of a standing and three dynamic workstations on computer task performance and cognitive function tests. Applied Ergonomics 2014;45:1570-8.
[7] Garber CE, Blissmer B, Deschenes MR, Franklin BA, Lamonte MJ, Lee I-M, Nieman DC, Swain DP. Quantity and quality of exercise for developing and maintaining cardiorespiratory, musculoskeletal, and neuromotor fitness in apparently healthy adults: Guidance for prescribing exercise. Med Sci Sports Exerc 2011;43(7):1334-59.

[8] Thompson WG, Foster RC, Eide DS, Levine JA. Feasibility of a walking workstation to increase daily walking. $\mathrm{Br} \mathrm{J}$ Sports Med 2008;42:225-8.

[9] Thompson WG, Levine JA. Productivity of transcriptions using a treadmill desk. Work 2011;40(4):473-7.

[10] Carr LJ, Walaska KA, Marcus BH. Feasibility of a portable pedal exercise machine for reducing sedentary time in the workplace. Br J Sports Med 2011;46:430-5.

[11] Foster C, Hillsdon M, Thorogood M. Interventions for promoting physical activity. Cochrane Database of Systematic Reviews. 2005;(1):Art. No. CD003180.

[12] Kahn EB, Ramsey LT, Brownson RC. The effectiveness of interventions to increase physical activity: A systematic review. Am J Prev Med 2002;22(4):73-107.

[13] Corlett EN. Background to sitting at work: Research-based requirements for the design of work seats. Ergonomics 2006;49:1538-46.

[14] Levine JA, Vander Weg MW, Hill JO, Klesges RC. Nonexercise activity thermogenesis: The crouching tiger hidden dragon of societal weight gain. Arterioscler Thromb Vasc Biol 2005;26:729-36.

[15] Hamilton MT, Healy GN, Dunstan DW, Zderic TW, Owen $\mathrm{N}$. Too little exercise and too much sitting: Inactivity physiology and the need for new recommendations on sedentary behavior. Curr Cardiovasc Risk Rep 2008;2;292-8.

[16] Duvivier BMFM, Schaper NC, Bremers MA, van Crombrugge G, Menheere PPCA. Minimal intensity physical activity (standing and walking) of longer duration improves insulin action and plasma lipids more than shorter periods of moderate to vigorous exercise (cycling) in sedentary subjects when energy expenditure is comparable. PLoS ONE 2013;8(2):e55542. doi:10.1371/journal.pone.0055542 